\title{
Cardiovascular diseases mortality and alcohol control policy in Lithuania: exploring a possible link
}

\author{
Ricardas Radisauskas ${ }^{1,2^{*}}$, Kawon Victoria Kim ${ }^{3,4}$, Shannon Lange ${ }^{3,5}$, Vaida Liutkute-Gumarov ${ }^{6}$, \\ Olga Mesceriakova-Veliuliene ${ }^{7}$, Janina Petkeviciene ${ }^{6,8}$, Mindaugas Stelemekas ${ }^{6,8}$, Tadas Telksnys ${ }^{6}$, \\ Alexander $\operatorname{Tran}^{3}$ and Jürgen Rehm $3,4,5,9,10,11,12$
}

\begin{abstract}
Background: Lithuania possesses one of the highest alcohol per capita consumption and has previously implemented alcohol control policies to reduce the alcohol-attributable burden. The aim of this study was to investigate Lithuanian cardiovascular disease (CVD) mortality rate trends between 2001 and 2018 and to explore a possible link between CVD mortality rate and alcohol control policy implementation.

Methods: Lithuanian population mortality and alcohol consumption data for 2001-2018 were obtained from Statistics Lithuania and The State Register of Death Cases and Their Causes, Institute of Hygiene. Sex-specific CVD mortality rates were directly standardized to the European standard population by five-year age groups and categorized according to the ICD-10 codes for all CVDs (I00-199), ischemic heart disease (IHD) (I20-I25), cerebrovascular diseases (160-169) and alcoholic cardiomyopathy (ACM) (I42.6). Joinpoint regression analyses were performed to identify points of inflection to explore their alignment with five selected alcohol policy enactments.

Results: Overall, the 2001-2018 yearly mortality rates for all CVDs significantly decreased on average by $-1.6 \%$ (95\% Cl -2.0, - 1.2\%) among men and - 2.1\% (95\% Cl -2.5, - 1.8\%) among women. Yearly changes in all CVDs, IHD, cerebrovascular diseases and ACM mortality rates were insignificant prior to their respective critical year points in 2006, 2005, 2008 and 2007, but significantly decreased afterwards by an average of $-2.4 \%(95 \% \mathrm{Cl}-2.7,-2.0 \%)$, $1.6 \%(95 \% \mathrm{Cl}-2.1,-1.1 \%),-1.2 \%(95 \mathrm{Cl}-1.7,-0.6 \%)$ and $-4.5 \%(95 \% \mathrm{Cl}-7.3,-1.6 \%)$ among men, and by $-2.7 \%$ $(95 \% \mathrm{Cl}-3.0,-2.3 \%),-2.0 \%(95 \% \mathrm{Cl}-2.6,-1.4 \%),-1.8 \%(95 \% \mathrm{Cl} 2.4,-1.3 \%)$ and $-6.6 \%(95 \% \mathrm{Cl}-10.7,-2.2 \%)$ among women, respectively. The changes in the mortality rate trends for all CVDs, IHD, cerebrovascular diseases and especially ACM coincided with alcohol policies enacted on the January 1, 2008, January 1, 2009, April 1, 2014 and March 1, 2017.
\end{abstract}

\footnotetext{
* Correspondence: ricardas.radisauskas@|smuni.lt

${ }^{1}$ Department of Environmental and Occupational Medicine, Faculty of Public Health, Lithuanian University of Health Sciences, Tilzes str. 18, 47181 Kaunas, Lithuania

${ }^{2}$ Institute of Cardiology, Lithuanian University of Health Sciences, Sukileliu av. 15, 50162 Kaunas, Lithuania

Full list of author information is available at the end of the article
}

(c) The Author(s). 2021 Open Access This article is licensed under a Creative Commons Attribution 4.0 International License, which permits use, sharing, adaptation, distribution and reproduction in any medium or format, as long as you give appropriate credit to the original author(s) and the source, provide a link to the Creative Commons licence, and indicate if changes were made. The images or other third party material in this article are included in the article's Creative Commons licence, unless indicated otherwise in a credit line to the material. If material is not included in the article's Creative Commons licence and your intended use is not permitted by statutory regulation or exceeds the permitted use, you will need to obtain permission directly from the copyright holder. To view a copy of this licence, visit http://creativecommons.org/licenses/by/4.0/ The Creative Commons Public Domain Dedication waiver (http://creativecommons.org/publicdomain/zero/1.0/) applies to the data made available in this article, unless otherwise stated in a credit line to the data. 
Conclusions: Yearly mortality rates for all CVDs, IHD, cerebrovascular diseases and ACM have declined in Lithuania between 2001 and 2018, and declining trends were more prominent in women than in men. Among the ICD-10 CVD categories investigated, the points of inflection identified for the ACM mortality rate trend coincided best with the selected alcohol policy enactment dates.

Keywords: Cardiovascular diseases, Mortality, Alcohol consumption, Alcohol control policy, Trends, Sex, Age

\section{Background}

Following decades of decline globally, cardiovascular disease (CVD) mortality rates have been starting to stagnate in most high-income countries, and even increase in some [1]. In 2019, CVDs were responsible for more than 18.6 million deaths globally, 3.5 million of which were in high income countries [1].

Lithuania has been classified by the World Bank as a high-income country since 2012 but the agestandardized CVD mortality rate per 100,000 people is about 2.6 times greater than that of other high-income countries [2]. In fact, the age-standardized CVD mortality rate is higher in Lithuania than the average for all World Bank income classification groups, as well as the global average [2].

CVD mortality can be mostly attributable to biological risk factors, including arterial hypertension, dyslipidemia and diabetes [3-6], as well as certain health behaviors, such as smoking, unhealthy diet, physical inactivity and alcohol use [7-9]. The observation that Lithuania possesses one of the highest alcohol per capita consumption in tandem with the fact that alcohol use accounts for the highest proportion of CVD deaths and disabilityadjusted life years in Europe attests to the association between alcohol use and CVD mortality [10].

Long-term prospective studies have shown that there is a J-shaped association between CVD morbidity and mortality and alcohol use [11-13].

A meta-analysis of 83 prospective studies found that among 599,912 current drinkers, increased alcohol consumption was log-linearly associated with a lower risk of myocardial infarction (Hazard Ratio $=0.94,95 \%$ Confidence Interval (CI): 0.91-0.97) [14]. On the other hand, according to the NHANES cohort, alcohol use increased the risk of coronary artery disease by an average of $14 \%$ (Odds Ratio $=1.14,95 \%$ CI: $1.04-1.35$ ) among people under 55 years of age [14]. Heavy drinking, defined as consuming more than 4 drinks on any day or more than 14 drinks per week for men and consuming more than 3 drinks on any day or more than 7 drinks per week for women, is associated with a high risk of death from CVD [10]. Heavy alcohol use, especially among middleaged men, is a common cause of arterial hypertension, non-ischemic dilated cardiomyopathy (alcoholic cardiomyopathy), atrial fibrillation, and stroke (both ischemic and hemorrhagic) $[12,15]$.
There is a vast amount of literature that suggests alcohol control policy interventions, such as restrictions on the physical availability of alcohol, an increase of excise tax on alcoholic beverages, and alcohol advertising restrictions can reduce not only all-cause mortality [16], but also specifically CVD mortality [17]. Alcohol control policy is often in the spotlight of political and public debate in Lithuania. In fact, the Alcohol Control Law is one of the most frequently amended legal acts in Lithuanian legislative history with around 63 amendments since 1995 [18]. Not surprisingly, there have been fluctuations between a more conservative stance on alcohol and liberalization, which is suspected to be reflected in the alcohol-related harm trends in Lithuania.

The aim of this study was to investigate the CVD mortality rate trends in Lithuania over the past 18 years (2001-2018) and explore a possible link between CVD mortality rate and alcohol control policy implementation.

\section{Methods}

The current study uses an observational design, based on yearly CVD mortality data. CVD mortality trends were investigated according to the International Classification of Diseases 10th Revision (ICD-10) codes for all CVDs (I00-I99) and three other common CVDs - ischemic heart disease (IHD) (I20-I25), cerebrovascular diseases (I60-I69) and alcoholic cardiomyopathy (ACM) (I42.6) [19]. Population mortality data for 2001-2018 were obtained from Statistics Lithuania [20] and The State Register of Death Cases and Their Causes, Institute of Hygiene [21]. Data of recorded alcohol consumed per capita (RAPC) among males and females aged 15 years and older were obtained from Statistics Lithuania [20].

\section{Selection of key alcohol control policies}

Rehm et al. (2021) [22] have analyzed alcohol control policies implemented in Lithuania based on impact on affordability, expected immediate effect and general nature of restrictions on availability. The following five important timeline points that were identified by Rehm et al. (2021) [22] were also selected for this analysis:

1. January 1, 2008. Excise tax on alcohol beverages was increased by 10 to $20 \%$ and penalties for drunk- 
driving increased. TV and radio alcohol advertisements during the daytime were banned.

2. January 1, 2009. Excise tax was increased by 10 to 15\%. Tax exemption for small beer breweries was canceled and nighttime (10 p.m. to 8 a.m.) takeaway alcohol sales were prohibited.

3. April 1, 2014. Excise tax was increased by $1 \%$ for ethyl alcohol and by 10 to $47 \%$ for other types of alcohol beverages.

4. March 1, 2017. Major excise tax was increased by over $111 \%$ for beer and wine, 91 to $94 \%$ for intermediate products and 23\% for ethyl alcohol.

5. January 1, 2018. Legal age to purchase and to consume alcohol was increased from 18 to 20 years. Nighttime takeaway alcohol sales were prohibited from 8 p.m. to 10 a.m. on Monday-Saturday, and from 3 p.m. to 10 a.m. on Sunday. A near-total ban on alcohol advertising was introduced.

\section{Statistical analysis}

All CVD, IHD, cerebrovascular diseases and ACM mortality rates were directly standardized by five-year age groups to the 2011-2030 European standard population [23].

Joinpoint regression analyses for all ages and a subgroup of 25-64 year-olds were performed to assess changes in the yearly sex specific mortality rates of selected diseases over the study period [24]. The Joinpoint analysis is a data-driven statistical technique that identifies bending points in data and applies various linear regression lines based on a preselected number of joining points [25]. Since there were a total 18 data points, no more than three joinpoints were identified for the analyses. Based on the maximum number of joinpoints, linear segments were fitted to the data. The Monte Carlo permutation method selects the smallest number of linear segments so that the additional junction point does not add a statistically significant linear trend [25].

For calculation of changes in mortality rates of CVD, IHD, cerebrovascular diseases and ACM, four joinpoint regression log scale models were fitted: $\log ($ mortality $)=$ $\beta \cdot$ year $+\alpha$ for each period.

The first model assumed zero joinpoints. One additional joinpoint was assumed for each successive joinpoint model so that the fourth model assumed three joinpoints.

The true number of joinpoints (from 0 to 3 ) was determined by means of the permutation test. The estimated annual percentage change (APC) was calculated from the optimal model.

An average annual percent change (AAPC) was calculated to determine a summary measure of the 20012018 CVD mortality trend. The AAPC is computed as a weighted average of the APCs from the Joinpoint model, with the weights equal to the length of the APC interval.

The 95\% CI was obtained in the usual manner from the standard error of the regression coefficient.

\section{Results}

Overall, mortality rates from all CVD as well as IHD, cerebrovascular diseases and ACM decreased between 2001 and 2018 (Table 1). All CVD mortality rate decreased from 1048.6 per 100,000 population in 2001 to 749.1 per 100,000 in 2018 , with an average rate of 925.6 per 100,000. The largest increase and decrease in CVD mortality rate from the previous year was found in 2005 $(+3.8 \%)$ and $2014(-5.4 \%)$, respectively.

The IHD mortality rate decreased from 684.3 per 100,000 population in 2001 to 474.7 per 100,000 in 2018 , with an average rate of 596.9 per 100,000 . The largest increase and decrease in IHD mortality rate from to the previous year was found in $2005(+4.7 \%)$ and 2017 $(-5.9 \%)$, respectively.

The mortality rate from cerebrovascular diseases decreased from 235.6 per 100,000 population in 2001 to 182.8 per 100,000 in 2018 , with an average rate of 219.7 per 100,000 . The largest increase and decrease in cerebrovascular diseases mortality rate from the previous year was found in $2006(+5.0 \%)$ and $2014(-8.0 \%)$, respectively.

The ACM mortality rate decreased from 5.0 per 100,000 population in 2001 to 1.8 per 100,000 in 2018 , with an average rate of 4.7 per 100,000. The largest increase and decrease in ACM mortality rate from to the previous year was found in $2007(+67.2 \%)$ and 2018 ($60.8 \%)$, respectively.

Between 2001 and 2018, the average RAPC in Lithuania was 13.01 of pure alcohol per capita among those aged 15 years and older, which varied from 10.51 in 2001 to 14.71 in 2011 and 2012. During a period from 2001 to 2009 , the RAPC increased by $32.4 \%$, while it decreased by $23.8 \%$ from 2012 to 2018 .

The Joinpoint regression analyses determined that one joinpoint, or critical year, was the ideal number of joinpoints for all CVD groups and all age groups. The results of the sex specific Joinpoint regression analyses are summarized in Table 2 for the overall age group, and in Table 3 for the 25-64 year-old age group.

The CVD mortality rates significantly decreased on average by $1.6 \%(95 \%$ CI $-2.0 ;-1.2)$ among men and by $2.1 \%$ (95\% CI $-2.5 ;-1.8)$ among women per year (Fig. 1a). 2006 was identified as the critical year for all CVD. The CVD mortality rates did not change significantly for both men and women from 2001 to 2006 . However, significant decreases in CVD mortality rates were observed from 2006 to 2018 for both men and 
Table 1 Age-standardized yearly mortality rates per 100,000 people for all cardiovascular diseases, ischemic heart disease, cerebrovascular diseases and alcoholic cardiomyopathy, and annual recorded alcohol consumption rates in liters and annual percent change

\begin{tabular}{|c|c|c|c|c|c|c|c|c|c|c|}
\hline \multirow[t]{2}{*}{ Year } & \multicolumn{2}{|c|}{$\begin{array}{l}\text { Cardiovascular diseases } \\
(100-199)\end{array}$} & \multicolumn{2}{|c|}{$\begin{array}{l}\text { Ischemic heart disease } \\
(\text { (20-125) }\end{array}$} & \multicolumn{2}{|c|}{$\begin{array}{l}\text { Cerebrovascular diseases } \\
(160-169)\end{array}$} & \multicolumn{2}{|c|}{$\begin{array}{l}\text { Alcoholic } \\
\text { cardiomyopathy (142.6) }\end{array}$} & \multicolumn{2}{|c|}{$\begin{array}{l}\text { Recorded alcohol } \\
\text { consumption per } \\
\text { capita }\end{array}$} \\
\hline & $\begin{array}{l}\text { Cases/ } \\
100,000\end{array}$ & $\begin{array}{l}\% \\
\text { change }\end{array}$ & $\begin{array}{l}\text { Cases/ } \\
100,000\end{array}$ & $\begin{array}{l}\% \\
\text { change }\end{array}$ & $\begin{array}{l}\text { Cases/ } \\
100,000\end{array}$ & $\begin{array}{l}\% \\
\text { change }\end{array}$ & $\begin{array}{l}\text { Cases/ } \\
100,000\end{array}$ & $\begin{array}{l}\% \\
\text { change }\end{array}$ & $\begin{array}{l}\text { Value } \\
\text { (liter) }\end{array}$ & $\begin{array}{l}\% \\
\text { change }\end{array}$ \\
\hline 2001 & 1048.6 & & 684.3 & & 235.6 & & 5.0 & & 10.5 & \\
\hline 2002 & 1046.3 & -0.2 & 669.9 & -2.1 & 244.6 & 3.8 & 4.9 & -2.0 & 11.1 & 5.7 \\
\hline 2003 & 1025.1 & -2.0 & 661.9 & -1.2 & 235.2 & -3.8 & 5.2 & 6.5 & 11.3 & 1.8 \\
\hline 2004 & 1010.6 & -1.4 & 648.1 & -2.1 & 231.5 & -1.6 & 5.9 & 13.3 & 12.2 & 8.0 \\
\hline 2005 & 1049.5 & 3.8 & 678.3 & 4.7 & 235.6 & 1.8 & 5.8 & -0.9 & 12.5 & 2.5 \\
\hline 2006 & 1043.2 & -0.6 & 661.0 & -2.6 & 247.4 & 5.0 & 7.2 & 23.6 & 13.2 & 5.6 \\
\hline 2007 & 1015.2 & -2.7 & 644.3 & -2.5 & 231.0 & -6.6 & 9.7 & 34.9 & 13.9 & 5.3 \\
\hline 2008 & 968.8 & -4.6 & 612.6 & -4.9 & 236.3 & 2.3 & 7.5 & -23.2 & 13.9 & 0.0 \\
\hline 2009 & 929.7 & -4.0 & 584.6 & -4.6 & 228.8 & -3.2 & 4.2 & -44.0 & 13.1 & -5.8 \\
\hline 2010 & 927.7 & -0.2 & 602.4 & 3.0 & 222.9 & -2.6 & 4.3 & 2.7 & 13.5 & 3.1 \\
\hline 2011 & 883.0 & -4.8 & 569.8 & -5.4 & 216.4 & -2.9 & 4.0 & -6.9 & 14.7 & 8.9 \\
\hline 2012 & 868.6 & -1.6 & 566.9 & -0.5 & 210.5 & -2.7 & 4.6 & 14.9 & 14.7 & 0.0 \\
\hline 2013 & 857.6 & -1.3 & 559.9 & -1.2 & 215.0 & 2.1 & 3.4 & -25.8 & 14.5 & -1.4 \\
\hline 2014 & 811.4 & -5.4 & 533.4 & -4.7 & 197.8 & -8.0 & 3.3 & -2.6 & 14.2 & -2.1 \\
\hline 2015 & 837.8 & 3.3 & 555.2 & 4.1 & 201.6 & 1.9 & 2.9 & -11.4 & 14.0 & -1.4 \\
\hline 2016 & 809.6 & -3.4 & 533.8 & -3.9 & 195.7 & -2.9 & 2.8 & -4.8 & 13.2 & -5.7 \\
\hline 2017 & 778.5 & -3.8 & 502.3 & -5.9 & 185.1 & -5.4 & 2.5 & -12.1 & 12.3 & -6.8 \\
\hline 2018 & 749.1 & -3.8 & 474.7 & -5.5 & 182.8 & -1.2 & 1.8 & -25.1 & 11.2 & -8.9 \\
\hline
\end{tabular}

women by an average of $2.4 \%(95 \% \mathrm{CI}-2.7 ;-2.0)$ and $2.7 \%$ (95\% CI $-3.0 ;-2.3)$, respectively.

The mortality rates from IHD, cerebrovascular diseases and ACM significantly decreased for both men and women between 2001 and 2018. The IHD, cerebrovascular diseases and ACM mortality rates decreased each year by an average of $1.6 \%$ (95\% CI $-2.1 ;-1.1)$,
1.2\% (95 CI - $1.7 ;-0.6)$ and $4.5 \%$ (95\% CI $-7.3 ;-1.6)$ among men and by $2.0 \%(95 \%$ CI $-2.6 ;-1.4), 1.8 \%(95 \%$ CI $2.4 ;-1.3)$ and $6.6 \%(95 \%$ CI -10.7 ; - 2.2) among women, respectively (Fig. $1 \mathrm{~b}, \mathrm{c}$ and $\mathrm{d}$ ). The critical year points for IHD, cerebrovascular diseases and ACM were respectively 2005, 2008 and 2007. The mortality rates for IHD, cerebrovascular diseases and ACM significantly

Table 2 Trends in age-standardized mortality from cardiovascular diseases, ischemic heart disease, cerebrovascular diseases and alcoholic cardiomyopathy in all age Lithuanian men and women during 2001-2018 by the Joinpoint regression analysis

\begin{tabular}{|c|c|c|c|c|c|c|c|}
\hline \multirow[t]{2}{*}{ Disease code } & \multirow[t]{2}{*}{ Sex } & \multirow{2}{*}{$\begin{array}{l}\text { Joinpoints } \\
\text { (years) }\end{array}$} & \multicolumn{2}{|l|}{ Period 1} & \multicolumn{2}{|l|}{ Period 2} & \multirow{2}{*}{$\begin{array}{l}\text { All period (2001-2018) } \\
\text { AAPC } \\
(95 \% \mathrm{Cl})\end{array}$} \\
\hline & & & Years & $\begin{array}{l}\text { APC } \\
(95 \% \mathrm{Cl})\end{array}$ & Years & $\begin{array}{l}\text { APC } \\
(95 \% \mathrm{Cl})\end{array}$ & \\
\hline \multirow[t]{2}{*}{ Cardiovascular diseases (100-199) } & Men & 2006 & $2001-2006$ & $0.2(-1.0,1.4)$ & $2006-2018$ & $-2.4^{\mathrm{a}}(-2.7,-2.0)$ & $-1.6^{\mathrm{a}}(-2.0,-1.2)$ \\
\hline & Women & 2006 & $2001-2006$ & $-0.9(-2.1,0.3)$ & $2006-2018$ & $-2.7^{\mathrm{a}}(-3.0,-2.3)$ & $-2.1^{\mathrm{a}}(-2.5,-1.8)$ \\
\hline \multirow[t]{2}{*}{ Ischemic heart disease (120-125) } & Men & 2005 & $2001-2005$ & $0.2(-2.0,2.4)$ & $2005-2018$ & $-2.1^{\mathrm{a}}(-2.5,-1.7)$ & $-1.6^{\mathrm{a}}(-2.1,-1.1)$ \\
\hline & Women & 2005 & $2001-2005$ & $-0.9(-3.4,1.5)$ & 2005-2018 & $-2.3^{a}(-2.8,-1.9)$ & $-2.0^{\mathrm{a}}(-2.6,-1.4)$ \\
\hline \multirow[t]{2}{*}{ Cerebrovascular diseases (160-169) } & Men & 2008 & $2001-2008$ & $0.0(-1.1,1.2)$ & $2008-2018$ & $-2.0^{\mathrm{a}}(-2.7,-1.3)$ & $-1.2^{a}(-1.7,-0.6)$ \\
\hline & Women & 2008 & $2001-2008$ & $-0.4(-1.5,0.7)$ & $2008-2018$ & $-2.8^{\mathrm{a}}(-3.5,-2.1)$ & $-1.8^{\mathrm{a}}(-2.4,-1.3)$ \\
\hline \multirow[t]{2}{*}{ Alcoholic cardiomyopathy (142.6) } & Men & 2007 & $2001-2007$ & $9.4^{\mathrm{a}}(2.0,17.2)$ & $2007-2018$ & $-11.3^{\mathrm{a}}(-14.3,-8.2)$ & $-4.5^{\mathrm{a}}(-7.3,-1.6)$ \\
\hline & Women & 2007 & $2001-2007$ & $10.2(0.0,21.4)$ & $2007-2018$ & $-14.6^{\mathrm{a}}(-19.3,-9.6)$ & $-6.6^{\mathrm{a}}(-10.7,-2.2)$ \\
\hline
\end{tabular}

Models are fitted on log scale: $\log ($ mortality $)=\beta \cdot$ year $+\alpha$ for each period. $A P C$ denotes annual percentage change, $A A P C$ denotes average annual percentage change, $\mathrm{Cl}$ denotes confidence interval. Statistics marked with ${ }^{\mathrm{a}}$ are significant at the 0.05 level. 
Table 3 Trends in age-standardized mortality from cardiovascular diseases, ischemic heart disease, cerebrovascular diseases and alcoholic cardiomyopathy in 25-64 years' Lithuanian men and women during 2001-2018 years by the Joinpoint regression analysis

\begin{tabular}{|c|c|c|c|c|c|c|c|}
\hline \multirow[t]{2}{*}{ Disease code } & \multirow[t]{2}{*}{ Sex } & \multirow{2}{*}{$\begin{array}{l}\text { Joinpoints } \\
\text { (years) }\end{array}$} & \multicolumn{2}{|c|}{ Period 1} & \multicolumn{2}{|c|}{ Period 2} & \multirow{2}{*}{$\begin{array}{l}\text { All period (2001- } \\
2018) \\
\text { AAPC }(95 \% \mathrm{Cl})\end{array}$} \\
\hline & & & Years & $\operatorname{APC}(95 \% \mathrm{Cl})$ & Years & APC $(95 \% \mathrm{Cl})$ & \\
\hline \multirow[t]{2}{*}{ Cardiovascular diseases (100-199) } & Men & 2006 & $\begin{array}{l}2001- \\
2006\end{array}$ & $4.8^{\mathrm{a}}(1.9,7.8)$ & $\begin{array}{l}2006- \\
2018\end{array}$ & $-4.3^{a}(-5.0,-3.5)$ & $-1.7^{\mathrm{a}}(-2.6,-0.8)$ \\
\hline & Women & 2006 & $\begin{array}{l}2001- \\
2006\end{array}$ & $3.9^{a}(2.2,5.7)$ & $\begin{array}{l}2006- \\
2018\end{array}$ & $-5.2^{\mathrm{a}}(-5.7,-4.8)$ & $-2.6^{\mathrm{a}}(-3.2,-2.1)$ \\
\hline \multirow[t]{2}{*}{ Ischemic heart disease (I20-125) } & Men & 2006 & $\begin{array}{l}2001- \\
2006\end{array}$ & $3.6^{\mathrm{a}}(0.8,6.6)$ & $\begin{array}{l}2006- \\
2018\end{array}$ & $-4.1^{\mathrm{a}}(-4.9,-3.3)$ & $-1.9^{a}(-2.8,-1.0)$ \\
\hline & Women & 2006 & $\begin{array}{l}2001- \\
2006\end{array}$ & $5.4^{a}(2.6,8.4)$ & $\begin{array}{l}2006- \\
2018\end{array}$ & $-5.2^{\mathrm{a}}(-5.9,-4.4)$ & $-2.2^{\mathrm{a}}(-3.0,-1.3)$ \\
\hline \multirow[t]{2}{*}{$\begin{array}{l}\text { Cerebrovascular diseases } \\
(160-169)\end{array}$} & Men & 2007 & $\begin{array}{l}2001- \\
2007\end{array}$ & $2.1(-0.9,5.3)$ & $\begin{array}{l}2007- \\
2018\end{array}$ & $-3.9^{a}(-5.2,-2.6)$ & $-1.8^{\mathrm{a}}(-3.0,-0.6)$ \\
\hline & Women & 2010 & $\begin{array}{l}2001- \\
2010\end{array}$ & $\begin{array}{l}-1.2(-3.1 \\
0.8)\end{array}$ & $\begin{array}{l}2010- \\
2018\end{array}$ & $-6.6^{\mathrm{a}}(-9.2,-3.9)$ & $-3.8^{\mathrm{a}}(-5.2,-2.3)$ \\
\hline \multirow[t]{2}{*}{$\begin{array}{l}\text { Alcoholic cardiomyopathy } \\
\text { (142.6) }\end{array}$} & Men & 2007 & $\begin{array}{l}2001- \\
2007\end{array}$ & $\begin{array}{l}10.5^{a}(2.6 \\
19.0)\end{array}$ & $\begin{array}{l}2007- \\
2018\end{array}$ & $\begin{array}{l}-11.3^{\mathrm{a}}(-14.4,- \\
8.1)\end{array}$ & $-4.1^{\mathrm{a}}(-7.1,-1.1)$ \\
\hline & Women & 2007 & $\begin{array}{l}2001- \\
2007\end{array}$ & $\begin{array}{l}12.2^{\mathrm{a}}(1.2 \\
24.4)\end{array}$ & $\begin{array}{l}2007- \\
2018\end{array}$ & $\begin{array}{l}-15.1^{\text {a }}(-20.0,- \\
9.8)\end{array}$ & $-6.3^{a}(-10.7,-1.7)$ \\
\hline
\end{tabular}

Models are fitted on log scale: $\log ($ mortality $)=\beta \cdot$ year $+\alpha$ for each period. $A P C$ denotes annual percentage change, $A A P C$ denotes average annual percentage change, $\mathrm{Cl}$ denotes confidence interval. Statistics marked with ${ }^{\mathrm{a}}$ are significant at the 0.05 level.

decreased after their respective critical year points (Fig. $1 \mathrm{~b}$ and $\mathrm{c}$ ). IHD mortality rate decreased each year after 2005 by an average of $2.1 \%$ (95\% CI -2.5 ; - 1.7) among men and $2.3 \%(95 \% \mathrm{CI}-2.8 ;-1.9)$ among women, and cerebrovascular diseases mortality rate decreased each year after 2008 by an average of $2.0 \%$ (95\% CI -2.7 ; 1.3) among men and $2.8 \%$ (95\% CI -3.5; - 2.1) among women. The mortality rate for ACM increased significantly between 2001 and 2007 among men by an average of $9.4 \%(95 \%$ CI $2.0 ; 17.2)$ per year but significant changes were not observed among women for the same time period. However, ACM mortality rate decreased significantly after 2007 among men and women by an average of $11.3 \%(95 \%$ CI $-14.3 ;-8.2)$ and $14.6 \%(95 \%$ CI -19.3; - 9.6), respectively.

Among 25-64 year-old men and women, CVD mortality decreased significantly on average by $1.7 \%$ (95\% CI $-2.6 ;-0.8)$ and $2.6 \%(95 \%$ CI $-3.2 ;-2.1)$ per year, respectively, from 2001 to 2018 (Fig. 1a). 2006 was identified as the critical year for all CVD among the 25-64 year-old population. CVD mortality rates increased significantly between 2001 to 2006 by $4.8 \%$ (95\% CI 1.9; $7.8)$ in men and by $3.9 \%(95 \%$ CI $2.2 ; 5.7)$ in women, but significantly decreased on average by $4.3 \%$ (95\% CI -5.0 ; - 3.5) and $5.2 \%$ (95\% CI -5.7; - 4.8), respectively, between 2006 and 2018 (Table 3).

Between 2001 and 2018, mortality from IHD among both men and women aged 25 to 64 years decreased significantly on average by $1.9 \%$ (95\% CI -2.8 ; -1.0$)$ and $2.2 \%$ (95\% CI -3.0 ; - 1.3) per year, respectively (Fig. 1b). 2006 was identified as the critical year for IHD among the 25 to 64 year-old population. Mortality from IHD increased significantly between 2001 and 2006 among men and women by $3.6 \%(95 \%$ CI $0.8 ; 6.6)$ and $5.4 \%(95 \%$ CI 2.6 ; 8.4) per year, respectively, and decreased significantly on average by $4.1 \%(95 \% \mathrm{CI}-4.9 ;-3.3)$ and $5.2 \%$ (95\% CI -5.9; -4.4), respectively, from 2006 to 2018.

Between 2001 and 2018, mortality from cerebrovascular diseases among both men and women aged 25 to 64 years decreased significantly on average by $1.8 \%$ (95\% CI $-3.0 ;-0.6)$ and $3.8 \%(95 \%$ CI $-5.2 ;-2.3)$ per year, respectively (Fig. 1c). 2007 and 2010 were identified as the critical year for cerebrovascular diseases among 25 to 64 year-old men and women, respectively. Mortality from cerebrovascular diseases trends among men and women 25 to 64 years old were without significant changes until their respective joinpoints, after which cerebrovascular diseases mortality decreased significantly by an average of $3.9 \%(95 \%$ CI $-5.2 ;-2.6)$ and $6.6 \%(95 \%$ CI $-9.2 ;-3.9)$ per year, respectively.

Between 2001 and 2018, mortality from ACM among men and women aged 25 to 64 years decreased significantly on average by $4.1 \%(95 \%$ CI $-7.1 ;-1.1)$ and $6.3 \%$ (95\% CI -10.7; - 1.7) per year, respectively (Fig. 1d). 2007 was identified as the critical year for ACM among the 25 to 64 year-old population. Mortality from ACM increased significantly between 2001 and 2007 among both men and women by an average of $10.5 \%$ (95\% CI $2.6 ; 19.0)$ and $12.2 \%$ (95\% CI 1.2; 24.4), respectively. The ACM mortality rate for men and women then decreased significantly from 2007 to 2018 by an average of $11.3 \%$ (95\% CI $-14.4 ;-8.1)$ and $15.1 \%$ (95\% CI -20.0; - 9.8), respectively. 

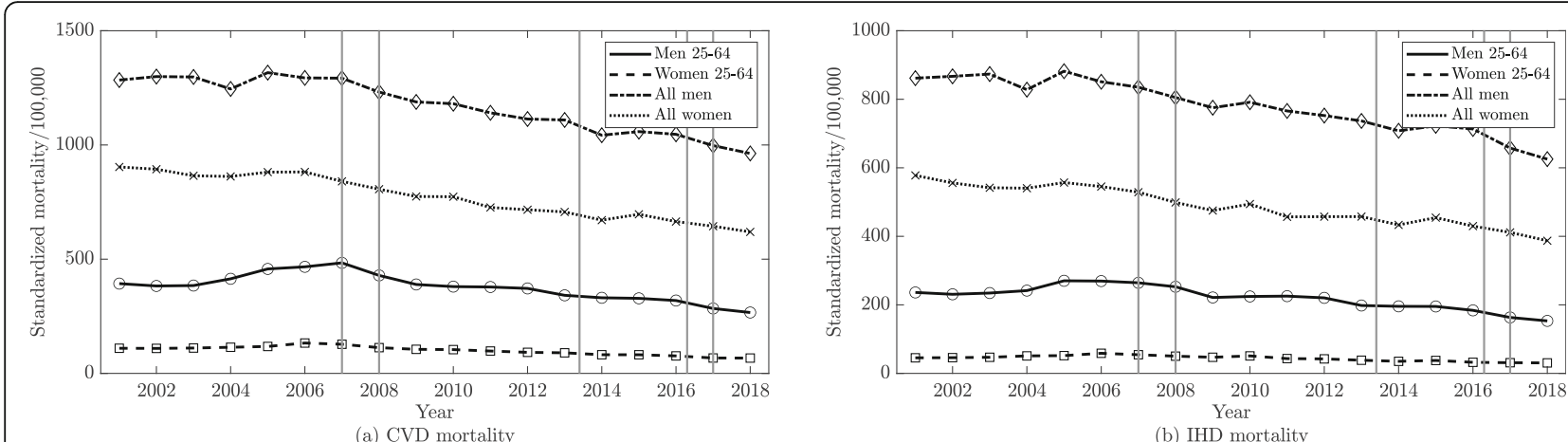

(a) CVD mortality

(b) IHD mortality
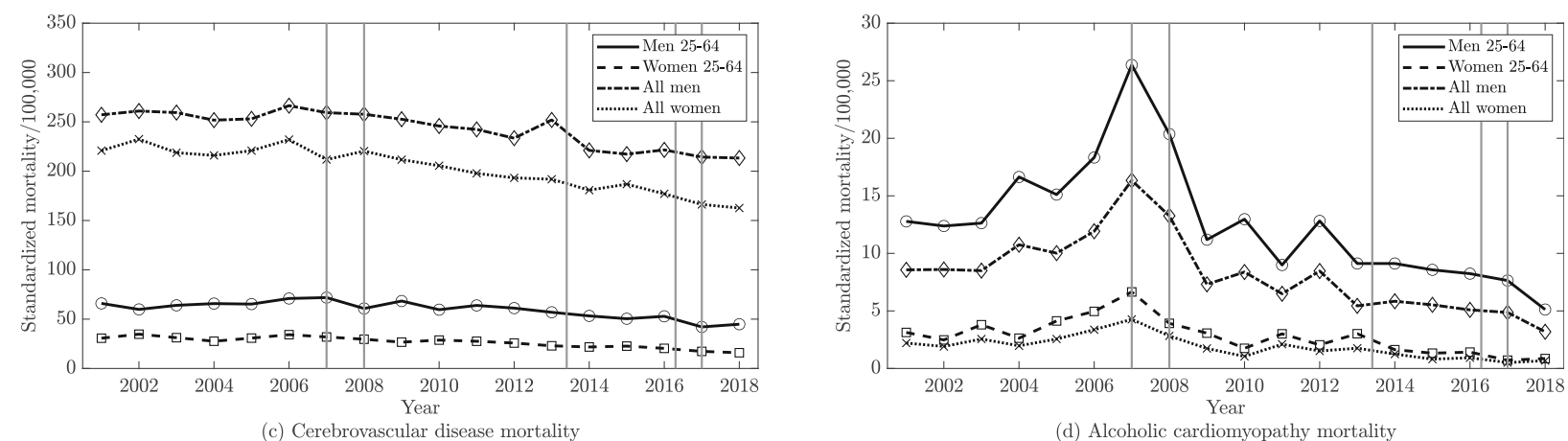

Fig. 1 The trends in age-standardized mortality rates from cardiovascular diseases, ischemic heart diseases, cerebrovascular diseases and alcoholic cardiomyopathy per 100,000 people among Lithuanian men and women in all ages and in 25-64 years' during 2001-2018. Note: Vertical lines illustrate time points of the five alcohol policies investigated in this analysis. As the mortality trends describes the end of the year state, each of the timeline policy points was visualized by setting it 1 year earlier with an aim to indicate an end of the year line before the initiation of a specific policy

Figure 1 shows that changes in the mortality rates trends for all CVDs, IHD, cerebrovascular diseases and especially ACM coincided with the alcohol policies enacted on the January 1, 2008, January 1, 2009, April 1, 2014 and March 1, 2017 in Lithuanian.

\section{Discussion}

Our study determined the age-standardized mortality rates from 2001 to 2018 for all CVD, IHD, cerebrovascular diseases and ACM to identify any potential links between the implementation of selected most effective alcohol control policies and changes in CVD mortality rates among Lithuanians. All CVD mortality significantly decreased from 2001 to 2018 in both sexes in Lithuania, however the declining trends were more prominent in women than in men. We identified 2005, 2006, 2007, 2008 and 2010 as critical years in CVD mortality rate trends, after which a significant decrease was observed.

The largest AAPC increase $(+3.8 \%)$ in all CVD mortality rates was found between 2004 and 2005, among all ages. As described by Miščikienè et al. (2020) [18], alcohol policies on taxation and advertising were loosened in 2001 and 2002, and further loosened in 2004 as part of legal harmonization with the European Union. This could have contributed to the increased affordability of alcohol beverages and consequently higher alcohol attributable burden.

Among the different CVD groups investigated, the changes in ACM mortality rate trends coincided best with the selected alcohol policy enactment dates. Direct link was observed when analyzing mortality from cerebrovascular diseases in the study population; mortality trends started to decrease significantly in average per year by $2.0 \%$ in men and by $2.8 \%$ in women after the implementation of alcohol control policies in 2008.

The analysis suggests that there might be a close relation between the implemented alcohol control policies and ACM mortality (especially in men), which is consistent with findings from Russia, a country with a similar experience in the field of alcohol control as Lithuania [26].

As we cannot exclude the supporting effects of the alcohol control policies on the overall declining trends in CVD, we cannot conclude that there was an effect either. The alcohol control policies which were anticipated to be highly impactful did not coincide with rapid declines of CVD mortality in women and men aged at least 15 years or among the 25 to 64 years-old population. 
The misalignment between the critical year points identified in this study and the policy implementation time points may be partly explained by recent improvements in the CVD risk profile of Lithuanians, which may have also contributed to the decreased mortality rates between 2001 and 2018 .

During the analyzed period, many changes occurred in the CVD risk profile of the Lithuanian population. In 2006, the National Programme for the Screening and Preventive Management of the High Cardiovascular Risk Individuals (40-54 years-old men and 50-64 years-old women) was launched in Lithuania and the prevalence of CVD risk factors has reduced since. The percentage of smoking cessation has increased significantly and a decreasing trend in smoking prevalence, especially among men was estimated [27, 28]. The prevalence of dyslipidemia and arterial hypertension has declined [29, 30], and a significant reduction in the prevalence of metabolic syndrome was identified among women [31]. The previous studies have confirmed that CVD prevention programs can reduce CVD mortality in the long term [32-34].

Furthermore, significant efforts have been made during the last two decades to improve the diagnosis, management, and treatment of acute myocardial infarction, including pre-hospital and treatment procedures during hospitalization and outpatient care [35, 36]. Nowadays, cardiac reperfusion rates used as a measure of the effectiveness of acute myocardial infarction treatment in Lithuanian hospitals are similar to those in Western and Northern European countries [37-39]. Also, the clinical diagnosis of patients with CVD has improved due to the application of the newest examination methodologies and diagnostic tools. All the above-mentioned measures could have played a role in a declining trend in CVD mortality.

Long-term behavioral changes were also observed during 2001 to 2018 in the Lithuanian population. Nutrition habits have improved: the consumption of animal fat declined, while the use of vegetable oil and consumption of fresh vegetables increased [40]. Based on the Health Interview Survey carried out by Statistics Lithuania, the prevalence of daily smoking in men decreased from $42.1 \%$ in 2005 to $29.9 \%$ in 2019 and remained stable in women (9.8\% in 2005 and $9.7 \%$ in 2019) [41].

\section{Study limitations}

Even though this study analyzed a relatively long period of time, it was subject to limitations. First, the study design controlled for underlying seasonal patterns and secular trends, but the use of ecological data can be considered as limitation. Second, it was impossible to make a proper full assessment of the possible effects of all other relevant confounding factors linked to observed trends and decrease in alcohol consumption. Thus, in any ecological analysis alternative explanations must be considered. Finally, we suspect under-reporting of alcohol-related death in death certificates, including alcoholic cardiomyopathy, due to high stigma related to the heavy drinking culture in Lithuania.

\section{Conclusions}

Our study showed that all CVD mortality, including IHD, cerebrovascular diseases and ACM, has declined in Lithuania over the past two decades, and declining trends were more prominent in women than in men, especially among individuals 25-64 years of age. Among the different CVD groups investigated, the onset of the declining ACM mortality rate trend coincided best with the selected alcohol policy enactment dates. Future studies are needed to estimate the impact of the alcohol control policies implemented in Lithuania on CVD mortality rates using more targeted statistical methods.

\section{Abbreviations}

AAPC: An average annual percent change; APC: Annual percentage change; ACM: Alcoholic cardiomyopathy; Cl: Confidence interval; CVD: Cardiovascular diseases; ICD-10: International Classification of Diseases 10th Revision; IHD: Ischemic heart diseases; RAPC: Recorded alcohol consumed per capita

\section{Acknowledgements}

This research was conducted as part of the project "Evaluation of the impact of alcohol control policies on morbidity and mortality in Lithuania and other Baltic states" and we would like to thank the whole team for their input to wider discussions in generating the research reported in this paper.

\section{Authors' contributions}

R.R., M.S, J.P. and J.R conceptualised the paper, and made substantial revisions to the entire manuscript with input from K.V.K, S.L., V.L.G and A.T. T.T. and O.M.V performed the data analysis and prepared the Tables and Figures. The draft background and discussion sections were prepared by R.R., J.R., V.L.G and K.V.K. R.R. wrote the first draft of the results section. M.S. and T.T. wrote the methods section of the manuscript. All authors, R.R., K.V.K., S. L, V.L.G., O.M.V., J.P., M.S., T.T., A.T. and J.R. read, reviewed and approved the final manuscript.

\section{Funding}

This work was supported by the National Institute on Alcohol Abuse and Alcoholism of the National Institutes of Health (NIAAA), grant number 1R01AA028224-01 and was conducted as part of the project "Evaluation of the impact of alcohol control policies on morbidity and mortality in Lithuania and other Baltic states". Content is the responsibility of the authors and does not reflect official positions of NIAAA or the National Institutes of Health.

\section{Availability of data and materials}

The datasets used and/or analysed during the current study are available from the corresponding author on reasonable request.

\section{Declarations}

Ethics approval and consent to participate

The study was conducted according to the guidelines of the Declaration of Helsinki.

All study protocols were approved by the Research Ethics Board of the Centre for Addiction and Mental Health, Institute for Mental Health Policy Research, Toronto, Canada on April 17, 2020, renewed on March 30, 2021 (REB decision letter no. 050/2020). 
The Lithuanian Bioethics Committee has confirmed that anonymized mortality data is not subject to the requirements of the Law on the Ethics of Biomedical Research in Lithuania (certificate no. 6B-17-91).

All methods were carried out in accordance with relevant guidelines and regulations.

\section{Consent for publication}

Not applicable.

\section{Competing interests}

The authors declare that they have no competing interests.

\section{Author details}

${ }^{1}$ Department of Environmental and Occupational Medicine, Faculty of Public Health, Lithuanian University of Health Sciences, Tilzes str. 18, 47181 Kaunas, Lithuania. ${ }^{2}$ Institute of Cardiology, Lithuanian University of Health Sciences, Sukileliu av. 15, 50162 Kaunas, Lithuania. ${ }^{3}$ Institute for Mental Health Policy Research, Centre for Addiction and Mental Health, 33 Ursula Franklin Street, Toronto, Ontario M5T 2S1, Canada. ${ }^{\text {DD }}$ alla Lana School of Public Health, University of Toronto, 155 College Street, Toronto, Ontario M5T 1P8, Canada. ${ }^{5}$ Campbell Family Mental Health Research Institute, Centre for Addiction and Mental Health, 33 Russell Street, Toronto, Ontario M5T 2S1, Canada. ${ }^{6}$ Health Research Institute, Faculty of Public Health, Lithuanian University of Health Sciences, Tilzes str. 18, 47181 Kaunas, Lithuania. ${ }^{7}$ Department of Health Management, Faculty of Public Health, Lithuanian University of Health Sciences, Tilzes str. 18, 47181 Kaunas, Lithuania. ${ }^{8}$ Department of Preventive Medicine, Faculty of Public Health, Lithuanian University of Health Sciences, Tilzes str. 18, 47181 Kaunas, Lithuania. ${ }^{9}$ Institute of Clinical Psychology and Psychotherapy, Technische Universität Dresden, Chemnitzer str. 46, 01187 Dresden, Germany. ${ }^{10}$ Department of Psychiatry, University of Toronto, 250 College Street, Toronto, Ontario M5T 1R8, Canada. ${ }^{11}$ Institute of Medical Science, University of Toronto, 1 King's College Circle, Toronto, Ontario M5S 1A8, Canada. ${ }^{12}$ Department of International Health Projects, Institute for Leadership and Health Management, I.M. Sechenov First Moscow State Medical University, Trubetskaya str., 8, b. 2, Moscow, Russian Federation 119992.

\section{Received: 20 July 2021 Accepted: 8 November 2021} Published online: 17 November 2021

\section{References}

1. Roth GA, Mensah GA, Johnson CA, Addolorato G, Ammirati E, Baddour LM, et al. Global burden of cardiovascular diseases and risk factors, 1990-2019: update from the GBD 2019 study. J Am Coll Cardiol. 2020;76(25):2982-3021. https://doi.org/10.1016/j.jacc.2020.11.010.

2. Global Health Data Exchange; http://ghdx.healthdata.org/gbd-results-tool.

3. Joseph P, Leong D, McKee M, Anand SS, Schwalm JD, Teo K, et al. Reducing the global burden of cardiovascular disease, part 1: the epidemiology and risk factors. Circ Res. 2017;121(6):677-94. https://doi.org/10.1161/CIRCRESA HA.117.308903.

4. Oparil S, Acelajado MC, Bakris GL, Berlowitz DR, Cífková R, Dominiczak AF, et al. Hypertension. Nat Rev Dis Primers. 2018;4(1):18014. https://doi.org/10.1 038/nrdp.2018.14

5. Einarson TR, Acs A, Ludwig C, Panton UH. Economic burden of cardiovascular disease in type 2 diabetes: a systematic review. Value Health. 2018;21(7):881-90. https://doi.org/10.1016/j.jval.2017.12.019.

6. Radisauskas R, Kirvaitiene J, Bernotiene G, Virviciute D, Ustinaviciene R, Tamosiunas A. Long-term survival after acute myocardial infarction in Lithuania during transitional period (1996-2015): data from populationbased Kaunas ischemic heart disease register. Medicina (Kaunas). 2019;55(7): 357. https://doi.org/10.3390/medicina55070357.

7. Daya NR, Rebholz CM, Appel LJ, Selvin E, Lazo M. Alcohol consumption and risk of hospitalizations and mortality in the atherosclerosis risk in communities study. Alcohol Clin Exp Res. 2020;44(8):1646-57. https://doi. org/10.1111/acer.14393.

8. Chang JY, Choi S, Park SM. Association of change in alcohol consumption with cardiovascular disease and mortality among initial-non-drinkers. Sci Rep. 2020;10(1):13419. https://doi.org/10.1038/s41598-020-70304-7.

9. Van de Luitgaarden IAT, Schrieks IC, De Bacquer D, van Oort S, Mirrakhimov EM, Pogosova $\mathrm{N}$, et al. EUROASPIRE $\mathrm{V}$ investigators group. Alcohol consumption patterns across Europe and adherence to the European guidelines in coronary patients: findings from the ESC-EORP EUROASPIRE V survey. Atherosclerosis. 2020;313:35-42. https://doi.org/10.1016/j.a therosclerosis.2020.09.009.

10. World Health Organization. Global status report on alcohol and health-2018. 2018.

11. Zhao J, Stockwell T, Roemer A, Naimi T, Chikritzhs T. Alcohol consumption and mortality from coronary heart disease: an updated Meta-analysis of cohort studies. J Stud Alcohol Drugs. 2017;78(3):375-86. https://doi.org/10.1 5288/jsad.2017.78.375

12. Zhang YB, Pan XF, Chen J, Cao A, Xia L, Zhang Y, et al. Combined lifestyle factors, all-cause mortality and cardiovascular disease: a systematic review and meta-analysis of prospective cohort studies. J Epidemiol Community Health. 2020; jech-2020-214050.

13. Di Castelnuovo A, Costanzo S, Bonaccio M, McElduff P, Linneberg A, Salomaa $V$, et al. MORGAM Study Investigators. Alcohol Intake and Total Mortality in 142,960 Individuals from the MORGAM Project: a populationbased study. Addiction. 2021. https://doi.org/10.1111/add.15593.

14. Kritanawong C, Kumar A, Wang Z, Narasimhan B, Mahtta D, Jneid H, et al. Coronary artery disease in the young in the US population-based cohort. Am J Cardiovasc Dis. 2020;10(3):189-94.

15. Degerud E, Høiseth G, Mørland J, Ariansen I, Graff-Iversen S, Ystrom E, et al. Association of coincident self-reported mental health problems and alcohol intake with all-cause and cardiovascular disease mortality: a Norwegian pooled population analysis. PLoS Med. 2020;17(2):e1003030. https://doi. org/10.1371/journal.pmed.1003030.

16. Štelemèkas M, Manthey J, Badaras R, Casswell S, Ferreira-Borges C, Kalèdiené $\mathrm{R}$, et al. Alcohol control policy measures and all-cause mortality in Lithuania: an interrupted time-series analyses. Addiction. 2021. https://doi.org/1 $0.1111 /$ add. 15470

17. Roerecke M, Rehm J. Alcohol consumption, drinking patterns, and ischemic heart disease: a narrative review of meta-analyses and a systematic review and meta-analysis of the impact of heavy drinking occasions on risk for moderate drinkers. BMC Med. 2014;12(1):182. https://doi.org/10.1186/s1291 6-014-0182-6.

18. Miščikienè L, Midttun NG, Galkus L, Belian G, Petkevičienè J, Vaitkevičiūtè J, et al. Review of the Lithuanian alcohol control legislation in 1990-2020. Int J Environ Res Public Health. 2020;17(10):3454. https://doi.org/10.3390/ijerph1 7103454.

19. ICD-10 codes; https://icd.who.int/browse10/2019/en\#/IX.

20. Lithuanian Statistical Department; https://osp.stat.gov.It/informaciniai-pra nesimai?articleld $=7641100$.

21. Lithuanian Hygiene Institute, 2019; https://stat.hi.lt/default.aspx?report_id=246.

22. Rehm J, Štelemékas M, Ferreira-Borges C, Jiang H, Lange S, Neufeld M, et al. Classifying alcohol control policies with respect to expected changes in consumption and alcohol-attributable harm: the example of Lithuania, 2000-2019. Int J Environ Res Public Health. 2021;18(5):2419. https://doi.org/1 0.3390/ijerph18052419.

23. Revision of the European Standard Population Report of Eurostat's task force; https://ec.europa.eu/eurostat/documents/3859598/5926869/KS-RA-13028-EN.PDF/e713fa79-1add-44e8-b23d-5e8fa09b3f8f.

24. Joinpoint Trend Analysis Software; https://surveillance.cancer.gov/joinpoint/

25. Kim HJ, Fay MP, Feuer EJ, Midthune DN. Permutation tests for joinpoint regression with applications to cancer rates. Stat Med. 2000;19(3):335-51. https://doi.org/10.1002/(SICI)1097-0258(20000215)19:3<335::AID-SIM336>3.0. CO;2-Z.

26. Pridemore WA, Chamlin MB, Kaylen MT, Andreev E. The effects of the 2006 Russian alcohol policy on alcohol-related mortality: an interrupted time series analysis. Alcohol Clin Exp Res. 2014;38(1):257-66. https://doi.org/1 0.1111 /acer.12256

27. Grabauskas V, Klumbiene J, Petkeviciene J, Sakyte E, Kriaucioniene V, Veryga A. Health behaviour among Lithuanian adult population, 2014. Kaunas: Lithuanian University of Health Sciences Press; 2015.

28. Rinkūnienè E, Petrulionienè Ž, Dženkevičiūtè $V$, Gimžauskaitè $S$, Mainelis A Puronaite $\mathrm{R}$, et al. Trends in cigarette smoking among middle-aged Lithuanian subjects participating in the primary prevention program between 2009 and 2016. Medicina (Kaunas). 2019;55(5):130. https://doi.org/1 0.3390/medicina55050130.

29. Tamosiunas A, Klumbiene J, Petkeviciene J, Radisauskas R, Vikhireva O, Luksiene $D$, et al. Trends in major risk factors and mortality from main noncommunicable diseases in Lithuania, 1985-2013. BMC Public Health. 2016; 16(1):717. https://doi.org/10.1186/s12889-016-3387-0. 
30. Kutkienè S, Petrulioniene Ž, Laucevičius A, Petrylaitè M, Maskeliūnaitė D, Puronaite $\mathrm{R}$, et al. Severe dyslipidemia and concomitant risk factors in the middle-aged Lithuanian adults: a cross-sectional cohort study. Lipids Health Dis. 2018:17(1):88. https://doi.org/10.1186/s12944-018-0731-7.

31. Laucevičius A, Rinkūnienè E, Petrulionienè Ž, Ryliškytè L, Jucevičienẻ A, Puronaite $\mathrm{R}$, et al. Trends in cardiovascular risk factor prevalence among Lithuanian middle-aged adults between 2009 and 2018. Atherosclerosis. 2020;299:9-14. https://doi.org/10.1016/j.atherosclerosis.2020.02.025.

32. Lee H, Cho J, Shin DW, Lee SP, Hwang SS, Oh J, et al. Association of cardiovascular health screening with mortality, clinical outcomes, and health care cost: a nationwide cohort study. Prev Med. 2015;70:19-25. https://doi. org/10.1016/j.ypmed.2014.11.007.

33. Bovet P, Chiolero A, Paccaud F, Banatvala N. Screening for cardiovascular disease risk and subsequent management in low and middle income countries: challenges and opportunities. Public Health Rev. 2015;36(1):13. https://doi.org/10.1186/s40985-015-0013-0

34. Colpani V, Baena CP, Jaspers L, van Dijk GM, Farajzadegan Z, Dhana K, et al. Lifestyle factors, cardiovascular disease and all-cause mortality in middleaged and elderly women: a systematic review and meta-analysis. Eur J Epidemiol. 2018;33(9):831-45. https://doi.org/10.1007/s10654-018-0374-z.

35. Laucevičius A, Rinkūnienè E, Skujaitè A, Petrulionienè Ž, Puronaitè R, Dženkevičiüte $\mathrm{V}$, et al. Prevalence of cardiovascular risk factors in Lithuanian middle-aged subjects participating in the primary prevention program, analysis of the period 2009-2012. Blood Press. 2015;24(1):41-7. https:/doi. org/10.3109/08037051.2014.961744.

36. Kotseva K, De Backer G, De Bacquer D, Rydén L, Hoes A, Grobbee D, et al. EUROASPIRE investigators. Lifestyle and impact on cardiovascular risk factor control in coronary patients across 27 countries: results from the European Society of Cardiology ESC-EORP EUROASPIRE V registry. Eur J Prev Cardiol. 2019;26(8):824-35. https://doi.org/10.1177/2047487318825350.

37. Barauskas M, Unikas R, Žiubryte G. Outcomes of in-hospital treatment of cardiac patients who survived cardiac arrest and experienced coronary angiography. Arch Med Sci Atheroscler Dis. 2018;3:e1-7. https://doi.org/10. 5114/amsad.2018.73212.

38. Puymirat E, Cayla G, Cottin Y, Elbaz M, Henry P, Gerbaud E, et al. Twentyyear trends in profile, management and outcomes of patients with STsegment elevation myocardial infarction according to use of reperfusion therapy: data from the FAST-MI program 1995-2015. Am Heart J. 2019;214: 97-106. https://doi.org/10.1016/j.ahj.2019.05.007.

39. Thrane PG, Kristensen SD, Olesen KKW, Mortensen LS, Bøtker HE, Thuesen L, et al. 16-year follow-up of the Danish acute myocardial infarction 2 (DANAMI-2) trial: primary percutaneous coronary intervention vs. fibrinolysis in ST-segment elevation myocardial infarction. Eur Heart J. 2020;41(7):84754. https://doi.org/10.1093/eurheartj/ehz595.

40. Kriaucioniene V, Klumbiene J, Petkeviciene J, Sakyte E. Time trends in social differences in nutrition habits of a Lithuanian population: 1994-2010. BMC Public Health. 2012;12(1):218. https://doi.org/10.1186/1471-2458-12-218.

41. Health of Population of Lithuania (edition 2020); https://osp.stat.gov.lt/ lietuvos-gyventoju-sveikata-2020/rukymas.

\section{Publisher's Note}

Springer Nature remains neutral with regard to jurisdictional claims in published maps and institutional affiliations.

Ready to submit your research? Choose BMC and benefit from:

- fast, convenient online submission

- thorough peer review by experienced researchers in your field

- rapid publication on acceptance

- support for research data, including large and complex data types

- gold Open Access which fosters wider collaboration and increased citations

- maximum visibility for your research: over $100 \mathrm{M}$ website views per year

At $\mathrm{BMC}$, research is always in progress.

Learn more biomedcentral.com/submissions 